\title{
Ertapenem Susceptibility in Septicaemia due to Extended Spectrum Beta Lactamase (ESBL) Organisms in Teaching Medical College and Hospital Covering Rural Community
}

\author{
Jegan Charlies $^{1 *}$, V. Mangayarkarasi ${ }^{2}$, A.R. Rukadikar ${ }^{3}$ and V. Anandi ${ }^{4}$ \\ ${ }^{1}$ Department of Microbiology, ${ }^{3}$ Department of Microbiology, Zydus Medical College \\ and Hospital, Dahod, Gujarat, India \\ ${ }^{2}$ Department of Microbiology, SRM Medical College Hospital and Research Centre, \\ Kancheepuram District, Tamil Nadu, India \\ ${ }^{4}$ Department of Microbiology, Vinayaka Mission's Medical College, Karaikal, \\ Pondicherry, India \\ *Corresponding author
}

\section{Key w ords}

Septicemia, Extended spectrum beta lactamase,

Ertapenem,

Antimicrobial sensitivity testing

Article Info

Accepted: 15 November 2018 Available Online: 10 December 2018

\section{A B S T R A C T}

ESBL producing clinical isolates of gram negative organisms are major burden in hospital as well as in the community. These organisms are the causative agent for septicemia. Carbapenem group (Imipenem and Ertapenem) are the drug of choice for treating such infections. Recently increased incidences of resistance to Imipenem were reported, that makes the management of sepsis difficult. Aim of the study was to evaluate the susceptibility pattern of ertapenem in ESBL producing gram negative bacilli isolated from patients with septicemia in a teaching medical college covering predominantly rural population. Hospital based prospective study was conducted at SRM Medical College Hospital and Research Centre, Potheri, Kancheepuram, from septicemia diagnosed cases. The blood samples were collected and processed by standard methods. Isolation and identification of organisms was done as per standard guidelines. Antimicrobial sensitivity was determined by Kirby Bauer's Disc diffusion method as per CLSI guidelines. Evaluation of susceptible pattern of ertapenem from imipenem resistant ESBL producing gram negative isolates was studied. Among 765, 416 (54.37\%) were male and 349 (45.62 $\%)$ were female. Of $765,114(14.9 \%)$ showed positive. Out of $114,52.66 \%(60 / 114)$ were gram positive organisms, $44.73 \%$ (51/114) were gram negative organisms and 2.63 $\%(3 / 114)$ were fungal isolates. Among 51 gram negative isolates, $16(31.37 \%)$ isolates were ESBL producers. Out of 16 ESBL isolates, $7(43.75 \%)$ were Imipenem resistant. Out of 7 Imipenem resistant, 5 (71.42\%) were ertapenem sensitive and $2(28.57 \%)$ were ertapenem resistant. Present study showed low-level ertapenem resistance in imipenem resistance ESBL producing gram negative isolates. Ertapenem may be a viable alternative to other carbapenems for the treatment of infections caused by ESBL producing clinical isolates. Clinical outcome studies are required to determine if ertapenem is effective for the treatment of infections caused by these organisms. 


\section{Introduction}

Septicemia means multiplication of microorganisms and production of toxins in blood stream. Bacteraemia may be unimicrobial or polymicrobial. Common pathogens causing septicaemia/bacteraemia are Staphylococcus aureus, Coagulase Negative Staphylococci, Escherichia coli, Klebsiella pneumoniae, Pseudomonas aeruginosa, Enterobacter cloacae, Salmonella species etc., and rare organisms like Brucella species, HACEK groups (Haemophilus species, Actinobacillus actinomycetemcomitans, Cardiobacterium hominis, Ekinella species and Kingella kingae), Candida species etc.,

Extended spectrum $\beta$-lactamase (ESBL)producing strains of Enterobacteriaceae have now emerged as a major problem in hospitalized as well as community-based patients. These organisms are responsible for a variety of infections, such as urinary tract infection, septicemia, hospital-acquired pneumonia, intra-abdominal abscess, brain abscess and device-related infections. ${ }^{(1)}$

ESBL are enzymes that mediate resistance to extended spectrum cephalosporins (Third generation).Production of extended spectrum $\beta$-lactamases (ESBL) by Gram-negative bacteria has become a major issue in the fields of clinical microbiology and infectious diseases in the past 5 years. $(2,34)$ Therapeutic options are few and include aminoglycosides, quinolones, piperacillintazobactam and carbapenems. ${ }^{(5)}$

Carbapenems (Imipenem and Meropenem) are the drugs of choice for the treatment of infections caused by ESBL-producing organisms. Ertapenem is a parenteral carbapenem that was licensed for once daily use in November 2001 in the USA and in April 2002 in Europe. ${ }^{(6)}$
Ertapenem has in vitro activity against ESBL producing gram negative bacteria. ${ }^{(7)}$ There are only 2 reports of its clinical efficacy in ESBL producing gram negative bacterial infections with few cases of bacteraemia. ${ }^{(8,9)}$ In this study we have evaluated its clinical efficacy in treating ESBL producing and other multi drug resistant gram negative bacteraemia.

\section{Materials and Methods}

Hospital based prospective study conducted at SRM Medical College Hospital and Research Centre, Potheri, District: Kancheepuram, Tamil Nadu, India during March 2012 to February 2013. The study group of patients was clinically diagnosed blood stream infections admitted in various units such as Intensive care units (ICU's) and health care units (Wards). The blood samples were collected and processed by standard methods. Isolation and identification of organisms was done as per standard guidelines. ${ }^{(\mathbf{1 0})}$ Antimicrobial sensitivity was determined by Kirby Bauer's Disc diffusion method as per CLSI guidelines. ${ }^{(11)}$ Staphylococcus aureus (ATCC 25923), E. coli (ATCC 25922) and Pseudomonas aeruginosa (ATCC 27853) were used as quality control throughout the study for culture and antimicrobial susceptibility testing. ESBL was screened by phenotypic confirmatory test, using Ceftazidime and Ceftazidime/Clavulanate combination disc. Ertapenem susceptibility was screened by double disc synergy test, using imipenem and ertapenem discs.

\section{Statistical analysis}

The results were expressed as percentages for analysis of various epidemiological details and for analyzing the distribution of different bacterial isolates and their sensitivity pattern. Microsoft excel was used for the interpretation of these results. 


\section{Results and Discussion}

Total 765 blood sample was collected during March 2012 to February 2013 from septicemia diagnosed cases. Among those 416 $(54.37 \%)$ were male while $349(45.62 \%)$ were female (Table 1).

Out of 765 samples, $114(14.9 \%)$ were culture positive and $651(85.09 \%)$ were culture negative. Out of $114,52.66 \%(60 / 114)$ were gram positive organisms, $44.73 \%$ (51/114) were gram negative organisms and $2.63 \%$ (3/114) were fungal isolates (Tables 2 ,
3 and 4). Out of 51 gram negative isolates, 16 $(31.37 \%)$ were ESBL producing isolates, which were seen predominantly in $E$. coli (50\%) followed by Pseudomonas aeruginosa (25\%) and Klebsiella pneumoniae (12.5\%) (Table 5).

Among 16 ESBL isolates 7 (43.75\%) were imipenem resistant. Out of 7 Imipenem resistant, $5(71.42 \%)$ were ertapenem sensitive and $2(28.57 \%)$ were ertapenem resistant. These 2 ertapenem resistant isolates also shows resistant in Ertapenem with 3amino phenyl boronic acid (Table 6)

Table.1 Age and sexwise distribution of patients

\begin{tabular}{|c|c|c|c|c|c|c|c|c|}
\hline \multirow{3}{*}{$\begin{array}{l}\text { No. of } \\
\text { patients } \\
(\mathrm{n}=765)\end{array}$} & \multicolumn{2}{|c|}{$<15$ Years } & \multicolumn{2}{|c|}{15 - 40 Years } & \multicolumn{2}{|c|}{40 - 60 Years } & \multicolumn{2}{|c|}{$>60$ Years } \\
\hline & Male & Female & Male & Female & Male & Female & Male & Female \\
\hline & $\begin{array}{c}153 \\
(58.95 \%)\end{array}$ & $\begin{array}{c}115 \\
(42.9 \%)\end{array}$ & $\begin{array}{c}87 \\
(58.3 \%)\end{array}$ & $\begin{array}{c}62 \\
(41.6 \%)\end{array}$ & $\begin{array}{c}149 \\
(53 \%)\end{array}$ & $\begin{array}{c}132 \\
(46.97 \%)\end{array}$ & $\begin{array}{c}27 \\
(40.2 \%)\end{array}$ & $\begin{array}{c}40 \\
(59.7 \%)\end{array}$ \\
\hline Total & \multicolumn{2}{|c|}{$268(35 \%)$} & \multicolumn{2}{|c|}{$149(19.47 \%)$} & \multicolumn{2}{|c|}{$281(36.73 \%)$} & \multicolumn{2}{|c|}{$67(8.75 \%)$} \\
\hline
\end{tabular}

Table.2 Distribution of gram positive organisms isolated from blood culture

\begin{tabular}{|c|l|l|}
\hline Organisms $(\mathrm{n}=60)$ & Name of the isolates & No .of Isolates and Percentage \\
\hline \multirow{5}{*}{ GPC } & Staphylococcus aureus & $11(18.33 \%)$ \\
\cline { 2 - 3 } & Enterococcus species & $6(10 \%)$ \\
\cline { 2 - 3 } & $\begin{array}{l}\text { Coagulase Negative staphylococci } \\
\text { (CoNS) }\end{array}$ & $3(60 \%)$ \\
\cline { 2 - 3 } & Streptococcus pyogens & $3(5 \%)$ \\
\cline { 2 - 3 } & Streptococcus pneumoniae & $2(3.33 \%)$ \\
\cline { 2 - 3 } & Other Streptococcus species & $2(3.33 \%)$ \\
\hline
\end{tabular}

Table.4 The distribution of fungus isolated from blood culture

\begin{tabular}{|l|l|l|}
\hline Organisms $(\mathrm{n}=3)$ & Name of the isolates & No .of Isolates and Percentage \\
\hline Fungus & Candida albicans & $2(66.66 \%)$ \\
\hline & Candida non albicans & $1(33.33 \%)$ \\
\hline
\end{tabular}


Table.3 Distribution of gram negative organisms isolated from blood culture

\begin{tabular}{|l|l|l|}
\hline Organisms $(\mathrm{n}=51)$ & Name of the isolates & No .of Isolates and Percentage \\
\hline \multirow{2}{*}{ GNB } & Escherichia coli & $17(33.33 \%)$ \\
\hline & Pseudomonas aeruginosa & $11(21.56 \%)$ \\
\hline & Klebsiella species & $9(17.64 \%)$ \\
\hline & Citrobacter species & $3(5.88 \%)$ \\
\hline & Enterobacter species & $3(5.88 \%)$ \\
\hline & Acinetobacter species & $3(5.88 \%)$ \\
\hline & Salmonella typhi & $2(3.92 \%)$ \\
\hline & Proteus vulgaris & $2(3.92 \%)$ \\
\hline Brucella melitensis & $1(1.96 \%)$ \\
\hline
\end{tabular}

Table.5 List of ESBL producing with Imipenem resistant Gram negative isolates

\begin{tabular}{|l|c|c|}
\hline Name of the isolates & $\begin{array}{l}\text { No .of ESBL producing } \\
\text { GNB } \begin{array}{c}\text { Isolates and } \\
\text { Percentage }(\mathrm{n}=16 / 51)\end{array}\end{array}$ & $\begin{array}{l}\text { No. of Imipenem } \\
\text { Isolates (n=7/16) }\end{array}$ \\
\hline Escherichia coli & $8(50 \%)$ & $3(42.85 \%)$ \\
\hline Pseudomonas aeruginosa & $4(25 \%)$ & $2(28.57 \%)$ \\
\hline Klebsiella species & $2(12.5 \%)$ & $1(14.28 \%)$ \\
\hline Citrobacter species & $1(6.25 \%)$ & $1(14.28 \%)$ \\
\hline Enterobacter species & $1(6.26 \%)$ & $0(00)$ \\
\hline Total & $16(100 \%)$ & $7(100 \%)$ \\
\hline
\end{tabular}

Table.6 Imipenem resistant with Ertapenem sensitive ESBL producing isolates

\begin{tabular}{|l|c|c|c|c|}
\hline $\begin{array}{l}\text { Name of the } \\
\text { isolates }\end{array}$ & $\begin{array}{l}\text { No. of } \\
\text { Imipenem } \\
\text { resistant } \\
\text { Isolates } \\
(\mathrm{n}=7 / 16)\end{array}$ & $\begin{array}{l}\text { No. of } \\
\text { Ertapenem } \\
\text { sensitive } \\
\text { isolates (n=5/7) }\end{array}$ & $\begin{array}{l}\text { No. of } \\
\text { Ertapenem } \\
\text { resistant } \\
\text { Isolates (n=2/7) }\end{array}$ & $\begin{array}{l}\text { Carbapenamase } \\
\text { production Ertapenem } \\
\text { and Ertapenem with 3 } \\
\text { amino phenyl boronic } \\
\text { acid }\end{array}$ \\
\hline $\begin{array}{l}\text { Escherichia coli } \\
\begin{array}{l}\text { Pseudomonas } \\
\text { aeruginosa }\end{array}\end{array}$ & $2(28.85 \%)$ & $2(28.57 \%)$ & $1(50 \%)$ & 0 \\
\hline $\begin{array}{l}\text { Citrobacter } \\
\text { species }\end{array}$ & $1(14.28 \%)$ & $2(28.57 \%)$ & 0 & -- \\
\hline $\begin{array}{l}\text { Klebsiella } \\
\text { species }\end{array}$ & $1(14.28 \%)$ & 0 & $1(50 \%)$ & -- \\
\hline Total & $7(100 \%)$ & $5(100 \%)$ & $2(100 \%)$ & 0 \\
\hline
\end{tabular}


Bacteremia/Septicemia is the leading infectious disease; consisting of $16 \%$ of world population and $21 \%$ of the world global burden of the diseases. (12) Recent worldwide laboratory based surveillance report said that an attributable mortality rate of $35-50 \%$ from bacteremia alone despite emergence of newer antibiotics and improvement in supportive care. (13) The prevalence of bacteremia, the common causative organisms causing this infection and its antibiotic resistant pattern, the morbidity and mortality in a rural population are under reported in most of the developing countries including India.

In the present study the prevalence of bacteremia was $14.90 \%$ among 765 patients of all age groups. The prevalence of bacteraemia varies from place to place and country to country, via: New Delhi $42.1 \%$, Chandigarh $13.17 \%$, Jordan $58.6 \%$ reported and Kenya $12.5 \%(\mathbf{1 4 , 1 5 , 1 6 , )}$

In the present study, $57.01 \%$ of male patients were affected by bacteremia, as compare to female patients $42.98 \%$. Most of the patients were in the age group of $40-60$ years (36.73\%), followed by $0-15$ years $(35 \%)$. Samples received from various ICU's (49.41\%) had more positive cultures $(59.64 \%)$ compared to other units. Among Gram positive organisms, Coagulase negative staphylococci were the predominant isolate (60\%), followed by Staphylococcus aureus (18.33\%), Streptococci pyogens (5\%), Streptococci pneumonia (3.33\%), other Streptococci species (3.33\%) and Enterococci species (10\%). Among Gram negative organisms, Escherichia coli was predominant pathogen (33.33\%), followed by Klebsiella pneumoniae (17.64\%), Citrobacter species (5.88\%), Enterobacter species (5.88\%), Pseudomonas aeruginosa (21.56\%), Acinetobacter species (5.88\%), Salmonella typhi (3.92\%) and Brucella species $1.96 \%$.
In recent south Indian study the gram positive organisms were $51.7 \%$ and Gram negative organisms were $48.3 \%$ in blood culture samples. In the same study, CoNS were most frequent isolates (29.8\%) followed by Pseudomonas aeruginosa (19.9\%). Other organisms isolated in decreasing order of frequency were staphylococci aureus (16.9\%), Nonfermentive gram negative rods $(9.9 \%), E$. coli $(7.55 \%)$, Klebsiella pneumoniae (6.9\%), Streptococci species 4.5\%), Salmonella typhi (3.5\%) and one each of Proteus mirabilis and Streptococci pneumoniae. ${ }^{(17)}$

The present study shows that $2.63 \%$ of fungal organisms isolated from septicaemia patients, in which Candida albicans were predominant. All the isolates and proved organisms were subjected to antibiotic susceptibility test for the commonly used antimicrobials using modified Kirby Bauer disc diffusion method.

The $\beta$-lactamases are a large family of enzymes representing the major mechanism of resistance of bacteria against $\beta$-lactam antibiotics. More than $340 \quad \beta$-lactamase enzymes have been detected until 2004 . $^{(2,3,4)}$

Currently, carbapenems are regarded as the preferred agents for treatment of infections caused by ESBL- or AmpC-producing bacteria. ${ }^{(3,18)}$ In a study by Chitnis et al. ${ }^{(19)}$, $11 \%$ of multidrug-resistant isolates were susceptible to meropenem only. However, chromosomally mediated extended-spectrum serine proteases (group 2F) and metallo- $\beta$ lactamases active against carbapenems are not uncommon. Carbapenem resistance has been spreading in intensive care units among Acinetobacter spp. and Pseudomonas strains. In the short run, increased utilization of carbapenems against ESBL-producing bacteria will possibly lead to improved patient outcome, but, in the long run, to widely spread carbapenem resistance. Combination therapy, once multidrug resistance has occurred, was not effective in a study by 
Erdem et al. ${ }^{(20)}$ In our study, Out of 51 gram negative isolates, $16(31.37 \%)$ were ESBL producing isolates, which were seen predominantly in E. coli $(50 \%)$ followed by Pseudomonas aeruginosa (25\%) and Klebsiella pneumoniae (12.5\%). Among 16 ESBL isolates $7(43.75 \%)$ Pseudomonas was imipenem resistant. Out of 7 Imipenem resistant, $5 \quad(71.42 \%)$ were ertapenem sensitive and 2(28.57\%) were ertapenem resistant. These 2 ertapenem resistant isolates also shows resistant in Ertapenem with 3amino phenyl boronic acid.

In conclusion, Ertapenemcan be used as an alternative to other carbapenems for the treatment of infections caused by ESBL producing clinical isolates. Several studies are required to determine if ertapenem is effective for the treatment of infections caused by these organisms.

\section{References}

1. Mathur P, Kapil A, Das B, Dhawan B. Prevalence of extended spectrum beta lactamase producing Gram negative bacteria in a tertiary care hospital. Indian $\mathbf{J}$ Med Res 2002; 115:153-7.

2. Jacoby GA, Munoz-Price LS: Mechanisms of disease: the new $\beta$-lactamases. $\mathrm{N}$ Engl J Med 2005; 352: 380-391.

3. Rupp ME, Fey PD: Extended spectrumlactamase (ESBL)-producing Enterobacteriaceae. Drugs 2003; 63: 353365.

4. Shah AA, Hasan F, Ahmed S,Hameed A: Extended- $\quad$ spectrum $\quad \beta$-lactamases (ESBLs): characterization, epidemiology and detection. Crit Rev Microbiol 2004; 30: 25-32.

5. Nordmann P, Poirel L: Emerging carbapenemases in Gram-negative aerobes. Clin Microbiol Infect 2002; 8: 321-331.

6. Livermore DM, Sefton AM, Scott GM. Properties and potential of ertapenem. J
Antimicrob Chemother 2003; 52:331-44.

7. Hannah M. Wexler, In vitro activity of ertapenem: review of recent studies Journal of Antimicrobial Chemotherapy (2004) 53, Suppl. S2, ii11-ii21.

8. Teng CP, Chen HH, Chan J, Lye DC. Ertapenem for the treatment of extendedspectrum beta-lactamase-producing Gramnegative bacterial infections. Int $\mathbf{J}$ Antimicrob Agents. 2007 Oct; 30(4):3569. E pub 2007 Jul 13.

9. Bassetti M, Righi E, Fasce R, Molinari MP, Rosso R, Di Biagio A, Mussap M, Pallavicini FB, Viscoli C Efficacy of ertapenem in the treatment of early ventilator-associated pneumonia caused by extended-spectrum beta-lactamaseproducing organisms in an intensive care unit. J Antimicrob Chemother. 2007 Aug; 60(2): 433-5. Epub 2007 May 31.

10. Cheesbrough M. Microbiological tests. In: district laboratory practice in tropical countries part-2, low price ed. Cambridge; 2000:64-187.

11. CLSI - Clinical and Laboratory Standards Institute 2012. Performance standards for antimicrobial susceptibility testing. Nineteenth informational supplement. Wayne, PA, USA. CLSI; 2012.

12. S Bhattacharya. Blood culture in India: A proposal for a national programme for early detection of sepsis, IJMM Year : 2005, 23(4): 220-226.

13. Adolf W. Karchmer, Clinical Infectious Diseases, Volume 31, Issue Supplement_4, 1 September 2000, Pages S139-S143: Nosocomial Bloodstream Infections: Organisms, Risk Factors, and Implications. 14. Kumhar, G.D.V.G. Ramachandran, and P. Gupta, Bacteriological analysis of blood culture isolates from neonates in a tertiary care hospital in India. J Health PopulNutr, 2002. 20(4): p. 343-7.

15. Berkley JA, Lowe BS, Mwangi I, et al. Bacteremia among children admitted to a rural hospital in Kenya. N Engl \} Med 
2005; 352: 39-47.

16. Kaistha N, Mehta M, Singla N, Garg R, Chander J (2009) Neonatal septicaemia isolates and resistance patterns in a tertiary care hospital of North India. J Infect DevCtries 4: 055-057.

17. F. Vázquez, M.C. Mendoza , M.H. Villar, F. Pérez, F.J. Méndez, Survey of bacteraemia in a Spanish hospital over a decade (1981-1990), 1994, Volume 26, Issue 2, Pages 111-121.

18. Coudron PE, Hanson ND, Climo MW: Occurrence of extended-spectrum and AmpC _ - lactamases in bloodstream isolates of $K$. pneumoniae: isolates harbor plasmid-mediated FOX-5 and ACT-1
AmpC _ -lactamases. J. Clin. Microbiol 2003; 41: 772-777.

19. Chitnis S, Chitnis V, Hemvani N, Chitnis DS: In vitro susceptibility to meropenem and other antimicrobial agents among Gram-negative bacilli isolated from hospitalized patients in central India. Chemotherapy 2006; 52: 43-45.

20. Erdem I, Kucukercan M, Caran N: In vitro activity of combination therapy with cefepime, piperacillin-tazobactam, or meropenem with ciprofloxacin against multidrug-resistant Pseudomonas aeruginosa strains. Chemotherapy 2003; 49: 294-297.

\section{How to cite this article:}

Jegan Charlies, V. Mangayarkarasi, A.R. Rukadikar and Anandi, V. 2018. Ertapenem Susceptibility in Septicaemia due to Extended Spectrum Beta Lactamase (ESBL) Organisms in Teaching Medical College and Hospital Covering Rural Community. Int.J.Curr.Microbiol.App.Sci. 7(12): 1771-1777. doi: https://doi.org/10.20546/ijcmas.2018.712.206 